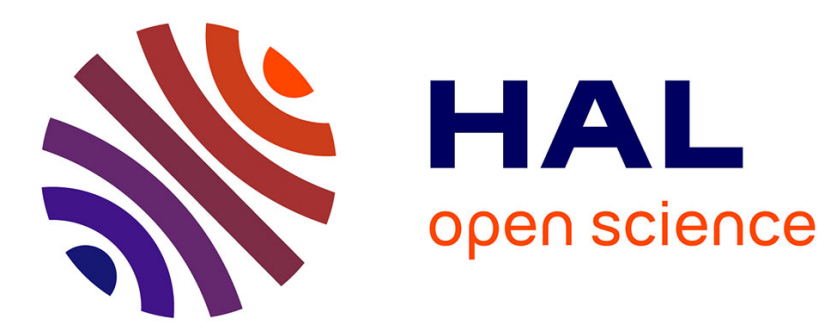

\title{
Territoire et politique en Europe du sud Évelyne Ritaine
}

\section{To cite this version:}

Évelyne Ritaine. Territoire et politique en Europe du sud. Revue Française de Science Politique, 1994, 44 (1), pp.75-98. 10.3406/rfsp.1994.394811 . halshs-00105474

\section{HAL Id: halshs-00105474 https://shs.hal.science/halshs-00105474}

Submitted on 29 Apr 2019

HAL is a multi-disciplinary open access archive for the deposit and dissemination of scientific research documents, whether they are published or not. The documents may come from teaching and research institutions in France or abroad, or from public or private research centers.
L'archive ouverte pluridisciplinaire HAL, est destinée au dépôt et à la diffusion de documents scientifiques de niveau recherche, publiés ou non, émanant des établissements d'enseignement et de recherche français ou étrangers, des laboratoires publics ou privés.

\section{(이)(\$)}

Distributed under a Creative Commons Attribution - NonCommercial - NoDerivatives| 4.0 


\title{
Territoire et politique en Europe du Sud
}

\section{Madame Evelyne Ritaine}

\section{Résumé}

concurrences politiques entre territoires ou entre forces politiques représentant des terri-toires ; jeu différentiel des représentations d'intérêts. La combinatoire de ces processus dote les territoires de capacités politiques très différenciées et différemment adaptées aux enjeux de la compétition européenne, qui peuvent être analysées comme des modalités différentes d'échange politique.

\begin{abstract}
Territory and politics in Southern Europe In the countries of Southern Europe (Spain, Italy), uncompleted nation-building has allowed the development of specific relations between pollues and territory. These relations are now regulated by territorial statutes provided for in the Constitutions. They are however driven by complex socio-policital processes : current articulation of territorialized political subcultures or of nationbound political cultures; political competition between territories or between political forces representing territories; particular operation of interest representation. The combination of these processes endows the territories with highly differentiated political capacities, variously adapted to the stakes of European competition, which can be analyzed as different modes of political exchange.
\end{abstract}

\section{Citer ce document / Cite this document :}

Ritaine Evelyne. Territoire et politique en Europe du Sud. In: Revue française de science politique, $44^{\mathrm{e}}$ année, $\mathrm{n}^{\circ} 1,1994 . \mathrm{pp}$. 75-99;

doi : https://doi.org/10.3406/rfsp.1994.394811

https://www.persee.fr/doc/rfsp_0035-2950_1994_num_44_1_394811

Fichier pdf généré le 25/04/2018 


\title{
TERRITOIRE ET POLITIQUE EN EUROPE DU SUD
}

\author{
EVELYNE RITAINE
}

L

'histoire européenne est-elle saisie d'un retour du refoulé, avec la résurgence politique des thèmes territoriaux? Dans le drame au centre de l'Europe avec la manifestation violente de la balkanisation politique. Dans un mouvement populiste pour l'Italie des Ligues régionales. De façon plus réformiste dans les pays qui s'interrogent sur les forces centrifuges qui travaillent leur territoire national (l'Espagne, la Belgique, la Grande-Bretagne) ou simplement sur l'assouplissement de la centralisation jacobine comme c'est le cas avec la régionalisation française. Un peu partout, enfin, sur un mode lancinant dans les résistances à la construction européenne ou, a contrario, dans les espoirs fédéralistes d'une Europe des régions: le rapport entre territoire et politique est redevenu un enjeu majeur. Il a suffi que la norme étatique et les organisations politiques nationales entrent en crise pour que se manifeste toute une série de revendications et d'enjeux liés au territoire, comme ils le sont souvent aussi aux thèmes de nation ou d'ethnie. Sans doute ces thèmes représententils à la fois des «remords» de l'histoire, nous enseignant un peu plus chaque jour que ce qui a été politiquement étouffé ressurgit inéluctablement, et des ressources symboliques pour des luttes politiques désormais privées de grandes idéologies mobilisatrices.

Ce ressurgissement des thèmes politiques territoriaux laisse l'analyse désarmée, car ceux-ci sont loin d'être de simples résurgences des régionalismes classiques, et se manifestent comme le produit de processus politiques complexes. En effet, ce qui signe désormais l'originalité de l'Europe de l'Ouest, par rapport à son propre passé, par rapport à ce qui se déroule ailleurs en Europe, est que les questions territoriales y soient partout régulées par des statuts territoriaux reconnus et parfois très avancés. L'existence de ces statuts, les stratégies politiques qui s'exercent en leur sein ou à leur propos transforment profondément les termes de ce débat. Une bonne illustration peut en être trouvée dans l'effet symbolique que l'accession à l'indépendance des Républiques baltes a eu sur les mouvements politiques autonomistes et nationalistes en Catalogne et au Pays basque. Cet exemple a été utilisé dans des surenchères politiques au sein même des institutions, ces communautés autonomes tentant d'obtenir de Madrid une autonomie encore plus large, d'autant que s'y activent des acteurs politiques concurrents ${ }^{1}$. De la même façon, les Ligues régionales italiennes utilisent l'image des conflits territoriaux en Europe de l'Est pour mettre en avant une revendication fédérale qui est

1. T. Maliniak, «L'Espagne face à l'explosion des nationalismes», Le Monde diplomatique, octobre 1991. 
avant tout un moyen d'élargir leur propre espace politique au-delà des régions d'origine ${ }^{1}$. L'existence de statuts territoriaux apparaît ainsi comme un élément de régulation politique : les conflits et les concurrences peuvent s'exercer dans la règle qu'ils définissent, voire chercher à la modifier. En ce sens, aujourd'hui en Europe de l'Ouest, la question territoriale est avant tout prise dans des stratégies politiques, tendance que la construction européenne encourage avec ce lieu commun qu'est l'Europe des régions, lieu commun précisément parce qu'il sert de ressource stratégique.

Ce constat n'épargne pas cependant l'analyse approfondie des faits territoriaux: les stratégies politiques n'ont pas la même signification selon qu'elles s'exercent à propos d'espaces socio-politiques définis par la présence d'une culture politique territorialisée ou à propos de simples espaces institutionnels, selon qu'elles interviennent dans des zones travaillées ou non par des mouvements nationalitaires, selon qu'elles utilisent des statuts régionaux et locaux plus ou moins puissants. Il ne se passe pas exactement la même chose en Catalogne et en Estrémadure, en Haut-Adige et en Ombrie, en Emilie-Romagne et en Ligurie. Or il y a longtemps que les sciences sociales, et en particulier la science politique, négligent ces thèmes. Depuis les travaux fondateurs sur les processus de construction des Etats-nations et sur les conditions du développement politique, marqués par les noms de S. Rokkan, C. Tilly, I. Wallerstein, la science du politique semble considérer de façon un peu hautaine que ce type de question ne relève plus que de l'histoire. De ce fait, le territoire se définit d'abord comme un rapport à l'histoire, comme un ensemble de dispositions sociales historiquement produites et reproduites, inscrites dans une localisation stable, comme «le produit d'une dialectique historique de la différence cumulative ${ }^{2}{ }^{2}$, entendant, par là, aussi bien des processus sociaux que des processus de construction politique, conçus comme l'instituant des mouvements sociaux et des stratégies politiques ou comme l'institué des constructions institutionnelles ${ }^{3}$. Il s'agirait donc de proposer, à titre programmatique, une actualisation des termes du débat, en montrant quels nouveaux problèmes analytiques se posent dans la période actuelle ${ }^{4}$.

1. R. Mannheimer (dir.), La Lega lombarda, Milan, Feltrinelli, 1991.

2. P. Bourdieu, «L'identité et la représentation. Eléments pour une réflexion critique sur l'idée de région $»$, Actes de la recherche en sciences sociales, 35, 1980.

3. «La centralisation n'est pas l'aménagement du territoire, mais avant tout l'aménagement des croyances», P. Legendre, Jouir du pouvoir. Traité de bureaucratie patriote, Paris, Minuit, 1976. Aussi n'emploie-t-on ici la notion de territoire que dans le sens de politiquement construit: d'un point de vue heuristique, il s'agit d'un qualificatif différentiel dans le temps et dans l'espace. Ce sens va bien au-delà de l'espace institutionnellement défini, comme de l'espace socio-économique. On est amené ainsi à ne pas traiter des différences de développement régional, qui ne correspondent pas forcément à des territoires politiques (par exemple le Mezzogiorno), même si ces inégalités sont parfois au principe des luttes politiques évoquées.

4. Cette réflexion a été entreprise à partir de travaux de recherche effectués pour le ministère de la Recherche et le PIRTTEM (1989-1991), et plus récemment pour la DATAR (Groupe Prospective et territoires) dans une recherche collective avec R. Balme, P. Garraud, V. Hoffmann-Martinot (Les politiques territoriales en Europe, Paris, L'Harmattan, 1994). Elle s'est enrichie des échanges avec J. Botella, P. Ceri, A. Mastropaolo, R. Balme et P. Garraud que nous tenons à remercier amicalement. 


\section{TERRITOIRE ET POLITIQUE: PROGRAMMATIQUE}

Comment aujourd'hui parvenir à tenir ensemble dans l'analyse tous les processus qui fondent la complexité des questions territoriales en Europe occidentale: culture politique territorialisée, construction politique du territoire, travail institutionnel sur le territoire? On peut penser que le potentiel politique des thèmes territoriaux est variable, en intensité et en genre, selon les combinatoires de ces trois processus. On se situe pour ce faire dans le paradigme de l'échange politique, entendu comme structure d'échange, analytiquement définie, entre le politique et le social: le territorial, sédimentation localisée du travail historique, est construit comme une des dimensions de cet échange. Il peut apparaître tour à tour comme une ressource renforçant les capacités d'échange, ou comme une ressource pour la contestation des termes de l'échange. Un bref rappel de l'évolution de ce paradigme permet d'y situer les questions territoriales. L'intérêt de ce paradigme est de placer la réflexion dans une perspective de sociologie politique, en construisant l'analyse en termes d'échange entre organisations complexes, les unes se situant dans le champ politique, les autres dépendant des différents champs de la société civile: il désigne la règle du jeu qui organise leur interdépendance et les assure face aux aléas de l'interaction. Il s'est d'abord développé à propos des sociétés où l'interaction entre les organisations politiques et les représentations d'intérêts est incontournable: l'Italie où s'est forgée la notion de scambio politico ${ }^{1}$, les pays européens de social-démocratie, où a été définie cette forme spécifique d'échange politique qu'est le néocorporatisme (l'Autriche, l'Allemagne, les Pays scandinaves) ${ }^{2}$. Il est également illustré, dans un sens plus organisationnel, par l'idée de relations de pouvoir construites comme des échanges de «possibilités d'action» par la sociologie des organisations: les «construits d'action collective» montrent comment sont produites les règles du jeu qui rendent possible la «coopération conflictuelle» entre organisations ${ }^{3}$. Enfin, un développement plus ambitieux de ce paradigme tente désormais d'englober les conceptions pluraliste et néocorporatiste de l'échange politique en les considérant comme degrés de complexité d'une interprétation conceptualisé comme «l'interdépendance politiquement induite et ordonnée d'une multiplicité de marchés et leur interprétation avec les espaces du politique », comme «échange politique généralisé » ${ }^{4}$.

1. A. Pizzorno, «Scambio politico e identità collettiva di classe», Rivista italiana di scienza politica, 7 (2), 1977; A. Pizzorno, «Political exchange and collective identity in industrial conflict», dans C.J. Chrouch, A. Pizzorno (eds), The resurgence of class conflict in Western Europe since 1968, Londres, Macmillan, 1978.

2. A. Cox, "The old and new testaments of corporatism: it is a political form or a method of policy making?», Political Studies, 36, 1988.

3. E. Friedberg, «Generalized political exchange, Organizational analysis, and public policy », dans B. Marin (ed.), Generalized political exchange. Antagonistic cooperation and integrated policy circuits, Francfort, Campus Verlag, Boulder, Westview Press, 1990.

4. B. Marin, «Generalized political exchange. Preliminary considerations», dans B. Marin (ed.), Generalized political exchange..., op. cit. 
Ce débat désormais classique sur les modalités de l'échange politique s'est étendu à l'étude des processus politiques territorialisés. Cette redécouverte est venue tout d'abord de pays où l'échange politique semble traditionnellement articulé sur des échanges plus liés au territoire. Elle est en outre due à un approfondissement des thèses néocorporatistes en direction des instances politiques territorialisées ${ }^{1}$. Logiquement, on en trouve l'illustration la plus aboutie en Italie où le débat sur l'échange politique et la discussion sur les thèses néocorporatistes ont été très vifs, et où la dynamique territoriale du politique est une évidence ${ }^{2}$. On a élaboré, à propos des territoires de la «troisième Italie ${ }^{3}$, la notion de neolocalismo, définie comme un mode de régulation politique, fondé sur la médiation localisée des intérêts et sur l'organisation locale de la négociation ${ }^{4}$. Dans une inspiration assez voisine, on parle en Espagne de néocorporatismes régionaux, notamment au sein des Comunidades autónomas les plus puissantes: le cas le mieux connu est celui de la Catalogne qui a entrepris une politique d'association des représentations d'intérêts à ses décisions $^{5}$. La terminologie est donc flottante, entre l'expression de néocorporatisme régional qui semble supposer un simple changement d'échelle dans un contexte néocorporatiste, et la notion de néolocalisme qui s'entend comme un processus spécifique. Pour en revenir vraiment aux termes de l'échange politique, pour comprendre comment le territoire est une forme de cet échange, il semble nécessaire d'étudier précisément les trois types de processus qui constituent un territoire politique. Celui de l'existence de cultures politiques territorialisées, qui relèvent d'une approche anthropologique et historique. Celui de la construction politique de territoires spécifiques par des opérateurs politiques collectifs, pris dans des rapports de concurrence, justifiable d'une étude stratégique. Celui du travail institutionnel sur l'espace du politique que peuvent cerner l'anthropologie symbolique comme l'analyse des politiques publiques.

Les sociétés sud-européennes (on se limitera, ici, aux exemples de l'Italie et de l'Espagne qui sont les mieux étudiés mais l'analyse pourrait être étendue aux autres pays du Sud européen) offrent un terrain particu-

1. P. Schmitter, L. Lanzalaco, «L'organizzazione degli interessi imprenditoriali a livello regionale», Stato e Mercato, 22, 1988.

2. On renvoie a l'ensemble des travaux pionniers de $S$. Tarrow, en particulier Between center and periphery: grassroots politicians in Italy and France, Londres, Yale University Press, 1977.

3. La recherche définit en Italie trois formations sociales aux modes de développement et de régulation socio-politique différenciés: la formation dite centrale, située au Nord-Ouest du pays, caractérisée par un développement industriel basé sur de grandes entreprises, une forte différenciation sociale et une mobilisation politique sectorielle; la formation dite marginale, située dans le Mezzogiorno, caractérisée par la dépendance économique, la précarité de l'emploi et le surdéveloppement du secteur tertiaire, la désagrégation sociale et une culture politique de type clientéliste; la formation dite périphérique, ou «troisième Italie», située dans le Nord-Est et le centre, caractérisée par un développement articulé sur les petites et moyennes entreprises, une moindre différenciation sociale et une culture politique du type culture civique. Cf. A. Bagnasco, Tre Italie: la problematica territoriale dello sviluppo italiano, Bologne, II Mulino, 1977.

4. C. Trigilia, «La regolazione localista: economica e politica nelle aree di piccola impresa», Stato e Mercato, 14, 1985.

5. J. Tornos Mass, «Regioni e rappresentanza degli interessi: il caso catalano», Stato e Mercato, 2, 1990. 
lièrement favorable à l'étude de ces questions: les conditions de leur développement économique (en particulier le maintien d'un «dualisme économique » parfois territorialement inscrit ${ }^{1}$ ) et de leur développement politique (l'inaboutissement de l'intégration nationale et les résistances locales à la centralisation étatique) y ont en effet laissé subsister de fortes tendances à la politisation territoriale.

En Italie, la question territoriale est dominée par le caractère tardif et artificiel de l'unité nationale, née d'une conjoncture diplomatique et militaire plus que d'un travail historique, laborieusement achevée entre 1860 et 1870 dans une situation de quasi-guerre civile, sans base idéologique forte, sans base sociale réelle. Dans ce contexte difficile, les thèses centralistes, inspirées de la centralisation napoléonienne, appliquée au Piémont au début du siècle, l'emportèrent dans le souci de stabiliser la situation politique du pays. Choix d'autant plus paradoxal que beaucoup de théoriciens du Risorgimento étaient favorables aux conceptions fédéralistes et que les premiers gouvernants de l'Etat italien étaient proches des thèses régionalistes d'inspiration anglo-saxonne. Choix d'autant plus lourd de conséquences que se trouvaient ainsi réunies des sociétés qui n'avaient ni le même niveau de développement économique ni le même type d'organisation sociale: le royaume piémontais, dit de Sardaigne, européen, développé, influencé par l'esprit des Lumières français; les nombreux duchés du centre et du Nord-Est de la péninsule, sous influence autrichienne, travaillés de particularismes économiques et culturels, mais tous dotés d'une agriculture prospère et d'une tradition de libertés municipales; les Etats de l'Eglise, au centre; le royaume des Deux-Siciles, possession des Bourbons, féodal et rural, aux mœurs très conservatrices, sans éducation populaire ni liberté civique. Choix d'autant plus vain, enfin, que l'appareil d'Etat italien n'est jamais parvenu à imposer une norme politique rationnelle, au sens wébérien du terme, face aux intérêts particuliers et localisés ${ }^{2}$.

«Marqué par la tare originelle d'une centralisation autoritaire, imposée contre la réalité diversifiée du pays, l'Etat italien, quel qu'ait été son statut au cours de la brève histoire unitaire du pays (monarchie libérale, dictature totalitaire, démocratie interventionniste et sociale), n'est jamais parvenu à s'enraciner durablement dans la conscience nationale ni à se poser en instrument de structuration de la société. Confronté à des particularismes locaux extrêmement vivaces, à des modes d'organisation sociale résistant aux interventions extérieures, à un tissu d'institutions concurrentes, orchestrées, au premier chef, par l'Eglise qui, durant des siècles, a façonné les mentalités et vertébré les communautés, l'Etat n'a cessé d'apparâtre aux yeux d'une majorité d'Italiens comme une réalité à la fois extérieure et abstraite, un produit d'importation dépourvu de racines nationales. ${ }^{3} \gg$

1. S. Berger, M.J. Piore, Dualism and discontinuity in industrial societies, Cambridge, Cambridge University Press, 1980.

2. S. Pallida, «L'anamorphose de l'Etat-nation: le cas italien», Cahiers internationaux de sociologie, 93, 1992.

3. D. Mazzega, J. Musitelli, L'organisation régionale en Italie, Paris, La Documentation française, 1980. 
En Espagne, les questions territoriales sont caractérisées par la contradiction entre une construction étatique, ancienne et autoritaire et le surgissement moderne de nationalismes dans ses périphéries ${ }^{1}$. Bâti dès l'origine sur une formule «pactiste» entre royaumes, l'Etat espagnol, occupé par des logiques impériales, n'a pas réussi à construire un projet intégrateur. L'identité espagnole s'est construite comme catholique et romaine, dominée par les valeurs de la Contre-Réforme, loin de toute définition nationale. Aussi la légitimité de l'Etat a-t-elle toujours été contestée, notamment lorsque s'est imposée une véritable centralisation étatique au $19^{e}$ siècle, par les mouvements carlistes, fédéralistes, cantonalistes, nationalitaires (en particulier en Catalogne et au Pays basque); ces derniers, très développés dans la lutte antifranquiste, ont très sérieusement menacé l'intégrité nationale et constitué un des enjeux majeurs de la transition démocratique. A l'époque contemporaine, l'Espagne a vécu sous un Etat faible, gouverné de façon autoritaire: aussi les différenciations et les tensions internes de la société espagnole se sont-elles intensifiées. «L'Espagne entra dans l'ère de l'industrie et de l'impérialisme capitaliste avec un appareil d'Etat inefficace, une série de privilèges et d'inégalités archaïques, et des mentalités hostiles à la modernité. Les enclaves périphériques industrialisées et de culture progressiste, ellesmêmes limitées, ne suffiraient pas à arracher le pays à son marasme. ${ }^{2}{ }^{»}$ Une transformation politique décisive s'est donc jouée avec la Constitution de 1978 qui, en instaurant un «Etat des autonomies», a totalement modifié les rapports centre-périphéries et le traitement de la question des nationalités ${ }^{3}$.

Ces deux cas de construction nationale problématique ont en commun un certain nombre de caractères. On sait l'influence, dans les pays européens du Sud, de la Contre-Réforme qui, entre une identité religieuse universaliste et des appartenances locales fortes, a laissé peu de place pour l'apparition de pré-nationalismes ${ }^{4}$. Ces deux Etats sont aussi passés, depuis le $19^{e}$ siècle, par une séquence de développement politique comparable, avec notamment de longs régimes autoritaires qui ont bloqué toutes les tendances centrifuges ${ }^{5}$. Enfin, leur structuration, tant sociale qu'économique, est restée marquée par le dualisme économique résultant de leur développement industriel tardif, et non compensé

1. J. Linz, «Early statebuilding and late peripheral nationalism against the State: the case of Spain», dans S.N. Eisenstadt, S. Rokkan (eds), Building States and nations, Londres, Sage, 1973.

2. S. Giner, «Nacionalismo étnico: centro y periferia en España», dans F. Hernández, F. Mercade (dir.), Estructuras sociales y cuestión nacional en España, Barcelone, Ariel, 1986.

3. P. Garraud, «Les relations centre-périphéries en Espagne», dans R. Balme, P. Garraud, V. Hoffmann-Martinot, E. Ritaine, Les politiques territoriales en Europe, op. cit.

4. S. Rokkan, «Dimensions of State-formation and national-building: a possible paradigm for research on variations within Europe», dans C. Tilly (ed.), The formation of national states in Western Europe, Princeton, Princeton University Press, 1975.

5. G. O'Donnell, P.C. Schmitter, L. Whitehead (eds), Transitions from authoritarian rule. Southern Europe, Baltimore, Londres, Johns Hopkins University Press, 1986. 
par des politiques étatiques: il se traduit par une fragmentation sociale et territoriale telle qu'on parle de trois Italie et de quatre Espagne ${ }^{1}$. Ce sont pourtant les différences dans ces processus qui sont les plus dynamisantes pour l'analyse. En Espagne, un centre politique, peu développé, s'est trouvé confronté à des périphéries plus industrialisées et plus riches: leur affrontement a pris la forme d'une opposition d'intérêts entre élites centrales, politiques et administratives, et élites périphériques, financières et industrielles. En Italie, c'est la partie la plus développée du pays, le Piémont, qui a fait l'unité, alors même qu'elle était en plein développement, et en y soumettant la partie la plus retardée du pays, le Mezzogiorno: l'alliance historique de la bourgeoisie industrielle du Nord et de l'aristocratie foncière du Sud a fondé l'expansion de la partie septentrionale sur le non-développement méridional ${ }^{2}$. L'actualité de ces pays atteste tous les jours de l'importance de ces contradictions fondatrices dans les conflits contemporains. En Italie, un long régime autoritaire puis une phase d'expansion économique exceptionnelle ont dissimulé jusqu'à aujourd'hui le pourrissement de la situation politique qu'entretient la contradiction Nord-Sud. L'échec de la rationalisation étatique est évident en Italie où la norme étatique, le fonctionnement de l'appareil d'Etat et le rapport au territoire national sont en état d'implosion: on y parle de «disunità ${ }^{3}$. En Espagne, au contraire, le passage récent à la démocratie a induit un traitement très souple des contradictions de l'intégration nationale qui, sous réserve des stratégies politiques qui le travaillent, laisse une chance à la définition d'une solution originale des tensions territoriales.

L'analyse, quant à elle, peut montrer que le différentialisme territorial est pris dans ces conflits, comme ressource dans l'échange politique. La richesse et la complexité des questions territoriales sont dues aux rapports circulaires qu'entretiennent des dynamiques socio-politiques territorialisées, le travail politique sur le territoire et la construction institutionnelle de l'espace socio-politique. Mais si les questions territoriales y sont particulièrement passionnantes, c'est aussi qu'elles sont étroite-

1. G. Fuà, «Les voies diverses du développement en Europe», Annales. Economies. Sociétés. Civilisations, 3, 1985; G. Arrighi (ed.), Semiperipheral development, the politics of Southern Europe in the twentieth century, Londres, Sage, 1985. Plus préciserment, on parle de trois Italie dans un sens très construit de formations socio-politiques différenciées; en Espagne, il s'agit plutôt d'un raisonnement sur le développement économique: l'Espagne en crise (Pays basque, Asturies, Cantabrie), celle qui se développe (Madrid et la côte méditerranéenne), celle qui survit (Galice, Andalousie), celle qui se dépeuple (Estrémadure, Manche et le reste du pays). Cf. J. Alcaide Inchausti, «Las cuatro España económicas y la solidaridad regional », Papeles de Economía española, 34, 1988.

2. E. Ritaine, «Italie: questions territoriales, territoire de questions», dans R. Balme, P. Garraud, V. Hoffmann-Martinot, E. Ritaine, Les politiques territoriales ..., op. cit.

3. G. Boccà, La disunità d'Italia, Milan, Garzanti, 1990. A ce propos, il sera sans doute nécessaire d'approfondir, pour le Sud de l'Italie, la notion de contrôle territorial par les réseaux clientélistes et par les réseaux mafieux, projet qui dépasse le cadre de ce texte. Cf. à ce sujet les remarques de A. Mastropaolo, «Tra politica e mafia. Storia breve di un latifondo elettorale», dans M. Morisi, Far politica in Sicilia, Milan, Feltrinelli, 1993. 
ment liées aux difficultés de l'intégration nationale, faiblesse de la construction de l'Etat-nation, crise contemporaine de la norme étatique et des organisations politiques nationales.

\section{CULTURES POLITIQUES TERRITORIALISÉES ET INTÉGRATION À L'ÉTAT-NATION}

La présence ou l'absence d'une culture politique dans un espace donné modifient les termes de l'échange politique: des milieux politiques homogènes produisent des capacités territorialisées de mobilisation, de consensus et de représentation des intérêts. La politisation du territoire y est le fruit d'une dynamique socio-politique, héritée de l'histoire et réactualisée dans les enjeux contemporains ${ }^{1}$. L'existence de cultures politiques territorialisées est liée aux conditions de l'intégration nationale et de la construction de l'Etat-nation: l'Espagne et l'Italie se caractérisent par des constructions nationales imparfaites qui ont laissé subsister des spécificités politiques territoriales dont l'existence est une ressource latente pour toute lutte politique. L'Europe du Sud est donc un terrain idéal pour faire apparâtre deux acceptions de la notion de cultures politiques territorialisées. La première, illustrée par le cas italien, est un construit de la recherche: une analyse anthropologique et historique ${ }^{2}$ atteste du fondement sociologique fort de l'inscription territoriale de traditions politiques; il est possible de les qualifier de cultures politicopolitiques territorialisées, entendant par là que leur dynamique n'est pour l'essentiel ni linguistique ni culturelle mais politique (les Italiens parlent de subcultures politiques locales, désignant ainsi leur inclusion dans un référent plus large). Dans ce type, c'est l'observation qui délimite le territoire de ces cultures, non la revendication des acteurs. Au contraire de ce qui se passe dans le deuxième type, plus important en Espagne, où se dévoilent les processus de construction par le travail politique de cultures politiques de dimension nationalitaire:

«Les luttes à propos de l'identité ethnique ou régionale, c'est-à-dire à propos des propriétés (stigmates ou emblèmes) liées à l'origine à travers le lieu d'origine et les marques durables qui en sont corrélatives ... sont

1. On emploie, ici, la notion de culture politique dans un sens paradigmatique, sans entrer dans les infinis débats qu'elle a suscités: on l'entend comme «produit d'un mécanisme de régulation des comportements politiques qui inculque aux individus des attitudes fondamentales forgées par l'histoire, et les conduit à partager, au-delà de leurs différences d'opinions politiques, des croyances communes sur la meilleure forme d'organisation sociale et de gouvernement», dans J. Lagroye, Sociologie politique, Paris, Presses de la Fondation nationale des sciences politiques, Dalloz, 1991 (souligné dans le texte).

2. Cf. «L'Etat en perspective», Etudes rurales, 101-102, 1986; P. Bois, Paysans de l'Ouest. Des structures économiques et sociales aux options politiques depuis l'époque révolutionnaire, Paris, La Haye, Mouton, 1960 ; C. Tilly, The Vendee, Cambridge, Harvard University Press, 1964 ; M. Agulhon., La République au village, Paris, Plon, 1970 ; S. Berger, Peasants against politics, Cambridge, Harvard University Press, 1972; C. Trigilia., Grandi partiti e piccole imprese, Bologne, Il Mulino, 1986. 
un cas particulier des luttes de classements, luttes pour le monopole du pouvoir de faire voir et de faire croire, de faire connaître et reconnaître, d'imposer la définition légitime des divisions du monde social et, par là, de faire et de défaire les groupes; elles ont en effet pour enjeu le pouvoir d'imposer une vision du monde social a travers les principes de division qui, lorsqu'ils s'imposent à l'ensemble d'un groupe, font le sens et le consensus sur le sens, et en particulier sur l'identité et l'unité du groupe ... Le discours régionaliste est un discours performatif, visant à imposer comme légitime une nouvelle définition des frontières et à faire connaître et reconnaître la région ainsi délimitée contre la définition dominante et méconnue comme telle, donc reconnue et légitime, qui l'ignore. L'acte de catégorisation, lorsqu'il parvient à se faire reconnaître ou qu'il est exercé par une autorité reconnue, exerce par soi pouvoir: les catégories «ethniques» ou «régionales», comme les catégories de parenté, instituent une réalité en usant du pouvoir de révélation et de construction exercé par l'objectivation dans le discours ${ }^{1}$.

Les premières semblent jouer un rôle d'intégration à la vie politique nationale par la périphérie, alors que les secondes sont bâties, du moins jusqu'à un certain point, sur la contestation de l'appartenance nationale.

\section{INTÉGRATION? DES SUBCULTURES POLITIQUES LOCALES}

Bien développée en Italie, l'étude des cultures politico-politiques vient du constat empirique que certaines parties du pays manifestent une orientation politique, entendue au double sens de stabilité électorale et de spécificité des processus institués de socialisation et de mobilisation politiques, remarquablement pérenne: les communautés locales du centre et du Nord-Est de l'Italie se sont, au fil du temps, bâti des traditions politiques; au centre, domine la tradition «rouge», c'est-à-dire laïque puis socialiste et communiste (pour 1'essentiel en Emilie-Romagne, Toscane, Ombrie, Marches); au Nord-Est, la tradition «blanche», c'est-à-dire catholique puis démocrate-chrétienne (pour l'essentiel en Vénétie, Lombardie, Frioul, Trentin) ${ }^{2}$. Tous les indicateurs envisagés depuis l'Unité (intensité et type de grèves en milieu agricole puis industriel, taux de syndicalisation et orientation idéologique des syndicats, existence de réseaux catholiques ou socialistes, tendances électorales) attestent de la continuité de ces orientations politiques. La question est de savoir par quels processus s'est réalisé cet investissement, comment sont assurées la stabilité et la reproduction de ces phénomènes. La réflexion prend donc ici une dimension anthropologique, en s'interrogeant sur la fonction dans texte)

1. P. Bourdieu., «L'identité et la représentation ...», art. cité (souligné dans le

2. On retrouve la logique du classement des provinces de la «troisième Italie » selon leur subculture politique dans $\mathbf{M}$. Caciagli, «Quante Italie ? Persistenza e trasformazione delle culture politiche subnazionale $»$, Polis, 3,1988 . Il faudrait évidemment discuter de la détermination de l'échelon pertinent d'observation : on indique les seules régions institutionnelles pour la clarté de l'exposé. En fait, les analyses électorales démontrent plutôt une stabilité électorale par province, et les études de sociologie politique sont plus centrées sur l'échelon municipal (commune, ou communes contigües), retrouvant ainsi la tradition du municipalisme italien. 
cette implantation de processus sociaux comme le mode de production, l'organisation du travail, le type de famille, l'orientation religieuse; mais aussi une dimension sociologique, en s'intéressant aux processus de socialisation, de mobilisation, d'organisation des intérêts. Elle cherche à montrer en quoi «la région, ce n'est pas l'espace mais le temps, l'histoire»'

La recherche italienne a particulièrement interrogé les processus d'implantation et de reproduction de ces subcultures ${ }^{2}$. Il apparaît qu'elles se sont formées entre 1'Unité et la première guerre mondiale autour des enjeux économiques de la modernisation du pays et des enjeux politiques de la formation de l'Etat italien. Le premier facteur discriminant de leur implantation est le type de structure économique existant dans ces zones au moment du démarrage de l'industrialisation du pays. Les effets de l'industrialisation et de l'économie de marché ont été en partie absorbés par une structure sociale fondée sur la famille et l'activité agricole. Les transformations économiques n'ont produit qu'une faible polarisation sociale et ont entraîné des comportements de mobilisation axés sur la famille et sur la société locale, donc fortement identitaires. Le second facteur discriminant est de nature idéologique: il s'agit de l'implantation différentielle de la tradition catholique au moment de 1'Unité. En Vénétie et dans les provinces voisines, la tradition catholique était très vive dans toutes les couches sociales. Le changement social entraîna une mobilisation valorisant l'identité à fondement religieux et une accentuation du rôle social et économique de l'Eglise. Dans le centre, la tradition catholique était beaucoup moins vive dans les campagnes, et un fort mouvement laïc travaillait les villes. L'hégémonie laïque, à laquelle s'articula ensuite un mouvement socialiste, s'imposa rapidement en Emilie-Romagne où la prolétarisation agricole était la plus nette, et plus lentement en Toscane, en Ombrie et dans les Marches où la mezzadria ${ }^{3}$ dominait. Un troisième facteur discriminant est la différence d'accès de ces subcultures au centre politique selon les époques: à l'exception des premières décennies de l'Etat italien, la subculture politique «blanche» a toujours eu un accès facile au centre alors que la subculture politique «rouge» se reproduisait toujours dans l'opposition; aussi la première est-elle plus marquée par une tendance à la délégation politique et à la protection de la communauté locale, alors que la seconde est caractérisée par une mobilisation organisée importante et des demandes plus sociales ${ }^{4}$. Aux élections de 1946, la résurgence de ces deux subcultures fut manifeste: les zones «rouges» votèrent très majoritairement pour le PCI et le PSI,

1. P. Bourdieu, «L'identité et la représentation ...», art. cité, commente ainsi les travaux de P. Bois, Paysans de l'Ouest ..., op. cit.

2. C. Trigilia, Grandi partiti ..., op. cit. Sur ces exemples italiens, cf. E. Ritaine, «Italie: questions territoriales, territoire des questions», dans Politiques territoriales en Europe, op. cit.

3. Différents types de fermage obligeant à fonctionner sur une organisation familiale du travail.

4. Ainsi les voies de socialisation secondaires sont-elles différenciées. Dans les années 1960 et 1970 , les régions de subculture «rouge» qui représentent $20 \%$ de la population italienne rassemblent entre 40 et $60 \%$ des adhérents aux représentations d'intérêts de gauche. Dans les régions «blanches», l'associationnisme est moindre; la socialisation est entretenue par le réseau dépendant de l'Eglise (institutions de crédit et d'assistance, presse catholique). Cf. C. Trigilia, Grandi partiti..., op. cit. 
cependant que les zones «blanches» portaient en masse leurs voix au nouveau parti catholique, la DC.

Depuis cette date, l'orientation politique de ces provinces s'est toujours maintenue. Quels qu'aient été ensuite les recentrages politiques et le recul de la mobilisation partisane, ces régions ont conservé une socialisation politique réticulaire (forte présence sociale des partis, syndicats et associations) et des dispositions au consensus local: leur capacité de régulation politique localisée est l'une des principales ressources de leur développement contemporain ". On a même pu montrer que ces cultures politiques territorialisées introduisent un élément majeur de différenciation dans les performances institutionnelles. On peut comprendre, donc, que les régions italiennes à statut ordinaire connaissent des écarts de performance institutionnelle considérables: ces différences sont dépendantes de variables économiques, de variables de stabilité sociale et surtout de variables liées à la culture politique. Les régions de forte culture civique et de bon rendement institutionnel (Emilie-Romagne, Lombardie, Vénétie, Toscane, Ombrie) se différencient des régions de culture politique clientéliste et de faible rendement institutionnel (Calabre, Molise, Campanie, Pouilles): «Les traditions d'activisme social et de solidarité civique expliquent le développement socio-économique et non l'inverse. La culture politique, et non la structure économique, est le déterminant principal du rendement institutionnel $»^{2}$.

Il est évident que l'ouverture culturelle et la modernisation économique ont peu à peu érodé, dans ces zones, ces ressources sociales héritées que sont l'organisation familiale, la valeur accordée au travail indépendant, le rôle politique de la communauté locale. La crise des partis politiques, manifestée par leur recul électoral progressif, a encore accentué l'instrumentation des régulations locales, incarnée par l'importance croissante des représentations d'intérêts. Il reste pourtant à mesurer si leur socialisation politique fortement réticulaire demeure une ressource de réactualisation de ces subcultures. Elle semble en effet pour le moment constituer un obstacle différentiel à l'implantation du mouvement protestataire des Ligues (Ligues lombarde, vénète, ligure). Selon les études consacrées à la plus importante d'entre elles, la Ligue lombarde, celle-ci s'est implantée avec une remarquable homogénéité territoriale à partir de communes traditionnellement dominées par la Démocratie chrétienne. La subculture politique «blanche» est en effet en recul depuis plus longtemps, aussi bien dans ses composantes idéologiques (recul de l'influence du catholicisme) que dans ses composantes politiques (recul électoral de la DC dans ses bastions du Nord-Est et discrédit national du parti de gouvernement). Le vote en faveur des Ligues s'enracine plus

1. E. Ritaine, «La modernité localisée? Leçons italiennes sur le développement régional», Revue française de science politique, 39 (2), 1989 ; E. Ritaine, «Territoire: espace du jeu politique», Quaderni, 13-14, 1991.

2. R.D. Putnam, «Rendimento istituzionale e cultura politica», Polis, 3, 1988 ; cf. aussi R.D. Putnam, R. Leonardi, R.Y. Nanetti, La pianta e le radici. Il radicamento del istituto regionale nel sistema politico italiano, Bologne, Il Mulino, 1985; R.D. Putnam (ed.), Making democracy work. Civic traditions in modern Italy, Princeton, Princeton University Press, 1993. 
aisément dans les zones de culture politique démocrate-chrétienne que l'électorat y trouve une possibilité de protestation anti-étatique et/ou un substitut à l'appartenance subculturelle traditionnelle. Parallelement, l'électorat communiste résiste d'autant mieux à l'attraction des Ligues qu'il se trouve dans une zone de culture communiste: l'existence d'un milieu politique homogène, d'une culture politique territorialisée semble ici un facteur tout à fait déterminant ${ }^{1}$. Cette hypothèse permet d'expliquer l'écologie de l'électorat des Ligues (qui s'étend de façon territorialement homogène et comme par capillarité) aussi bien que les efforts des Ligues pour reconstituer des réseaux d'appartenance (la Ligue lombarde vient, par exemple, de créer un syndicat à base territoriale) ${ }^{2}$. Par comparaison, la subculture «rouge», pourtant elle-même gravement atteinte par la crise de l'idéologie communiste et par le recul électoral de l'ex-PCI (devenu le PDS), semble mieux résister: une forte composante progressiste, solidariste et antifasciste demeure la marque de cette subculture quasi orpheline et continue a structurer les comportements politiques même si elle trouve plus difficilement une transcription électorale ${ }^{3}$. Le redressement du PDS, évident aux élections municipales partielles de décembre 1993, peut en ce sens renforcer la résistance de cette subculture de gauche.

On remarquera donc que, dans la crise du système politique italien, un des processus essentiels est ce recul des subcultures territoriales dont les traditions politiques articulées sur des représentations partisanes nationales constituaient un puissant facteur d'intégration à l'Etat-nation: la thèse de «la centralité des partis» en Italie est confirmée par l'échec même de cette fonction. Et l'on voit bien comment l'espace politique ainsi abandonné peut être occupé par n'importe quel acteur politique capable d'effectuer le travail politique nécessaire à l'investissement de l'hostilité envers les partis dans une forme de localisme protestataire dont la logique est tout autre: le signe territorial peut être inversé à la faveur de la crise politique nationale ${ }^{4}$.

1. Ce que notait déjà G. Sani, «Political traditions as contextual variables: partisanship in Italy», American Journal of Political Science, 20, 1976.

2. P. Natale, «Lega lombarda e insediamento territoriale: un'analisi ecologica», dans R. Mannheimer (dir.), La Lega lombarda, op. cit.

3. C. Baccetti, M. Caciagli, «Dopo il PCl e dopo l'URSS. Una subcultura rossa rivisitata», Polis, 3, 1992. Il faudra cependant relativiser cette analyse en restant attentif au fait que la Ligue lombarde réussit à s'implanter dans certaines zones d'Emilie-Romagne (alors que ces résultats demeurent modestes dans les autres zones «rouges»): aux élections pour la Chambre des députés d'avril 1992, elle obtient $7 \%$ des suffrages exprimés dans la circonscription Bologne-Ferrare-Ravenne-Forli (DC: 18,2 \%; PDS : 34,2 \%; Rifondazione comunista: 6,7 \%; PSI : $11 \%$ ), et 13,2\% dans la circonscription ParmeModène-Placenza-Reggio Emilia (DC: $21,3 \%$; PDS : $30,2 \%$; Rifondazione comunista : $7,5 \%$; PSI: 10,1 \%). Cf. A. Di Virgilio, «Le elezioni in Italia», Quaderni dell'Osservatorio elettorale, $28,1992$.

4. Pour une approche sociologique, basée sur la notion de lien social, cf. B. Poche, «Fondements sociologiques de l'auto-référence. Quelques exemples européens», dans «Identités, espaces, frontières», Espaces et sociétés, 70-71, 1992; cf. aussi les contributions au numéro spécial «Società e politica tra esodo e communità », Iter, 5-6, 1992. 


\section{CONTESTATION? DES CULTURES POLITIQUES NATIONALITAIRES}

L'analyse des cultures politiques nationalitaires ${ }^{1}$ est d'un tout autre ordre. On ne s'intéresse pas tant à un substrat anthropologique (bien que les fonctions de socialisation nationalitaire de la famille, du contexte local, du système d'enseignement mériteraient d'être examinées de près), ou à l'homogénéité et à la stabilité des pratiques politiques (encore que ce ne soit pas à exclure dans certaines zones), qu'à la construction, effectuée par le travail politique, d'un référent nationalitaire. Quelles que soient ses incarnations idéologiques, qu'on s'y oppose ou qu'on y adhère, ce référent structure les comportements politiques du territoire qu'il délimite, y compris ceux des forces politiques nationales, tenues de le prendre en compte: c'est la généralisation, voire la légitimité, de ce référent qui justifie l'emploi de la notion de culture politique nationalitaire. Aujourd'hui, ces cultures politiques sont moins au temps de la revendication qu'au temps de l'institutionnalisation. Les luttes matérielles et symboliques des mouvements nationalitaires ont effectué un travail politique de construction d'un territoire (c'est-à-dire des caractères culturels, au premier rang desquels la langue) qui a sédimenté ses effets depuis assez lontemps pour qu'il constitue lui-même un héritage culturel: dans les cas espagnol et italien, la légitimité de ces cultures (au sens anthropologique comme au sens politique) est acquise, tant par rapport au centre politique que dans les populations concernées. Les luttes politiques se déroulent désormais à propos des moyens par lesquels cette légitimité s'incarne, sujet sur lequel s'opposent des «statutaires» (application, voire extension, des statuts actuels) et des «rupturistes » (revendications de l'indépendance).

En Italie, le seul cas évident est celui du Haut-Adige, de langue et de culture majoritairement autrichiennes, structuré par un parti autonomiste (Südtiroler Volkspartei), par des organisations indépendantistes, et par un dense réseau d'associations qui travaillent l'identité régionale ${ }^{2}$; la vie politique de la province autonome de Bolzano (qui forme avec la province de Trente la région à statut spécial Trentin-Haut-Adige, instituée en 1948) est dominée par le thème nationalitaire, à tel point que les

1. On emploie cet adjectif pour désigner tous les mouvements revendiquant un statut territorial et politique sur la base de la spécificité de leur territoire, qu'ils envisagent comme moyen l'autonomie au sein de l'Etat-nation, le statut d'Etat fédéré ou l'indépendance.

2. Il existe en Italie d'autres cas de fortes spécificités linguistiques et de revendications autonomistes auxquels la Constitution italienne a d'ailleurs reconnu la qualité de régions à statut spécial (outre le Trentin-Haut-Adige, il s'agit du Val d'Aoste, du FrioulVénétie julienne, de la Sardaigne et de la Sicile). Cependant, l'action de leurs organisations autonomistes n'est importante que dans le Trentin-Haut-Adige et en Val d'Aoste. Dans le Trentin-Haut-Adige, le PPST (Partito populare sudtirolese) rassemble 31,1\% des suffrages exprimés (DC: $21 \%$ ); en Val d'Aoste, la Ligue Valle D'Aosta, 49,6 \% et le Gruppo Dolchi-Fosson 36,8\% (élections législatives d'avril 1992). Di Virgilio, «Le elezioni in Italia», art. cité. La Sicile, quant à elle, ne connaît plus de mouvements autonomistes depuis que le parti national qu'est la DC s'y est implanté par des réseaux denses de clientélisme. Sur la notion de «parti clientéliste de masse», cf. M. Caciagli, Democracia cristiana e potere nel Mezzogiorno. Il sistema democristiano a Catania, Florence, Guaraldi, 1977. 
italianophones $y$ ont des attitudes politiques défensives. Quant aux communautés autonomes espagnoles, elles posent un problème analytique intéressant dans la mesure où seules certaines d'entre elles ont été travaillées par de véritables mouvements nationalitaires. La Catalogne et le Pays basque ont ainsi intégré l'expérience historique de l'opposition nationalitaire, qui a été une des composantes de la «crise politique connue» que traverse ce pays depuis le $19^{e}$ siècle, déchiré entre des structures sociales traditionnelles et la rationalisation étatique.

Ce substrat nationalitaire, fait de la construction politique de la langue, de la culture et de l'histoire, est mobilisé dans des mouvements nationalitaires diversifiés en fonction des intérêts sociaux et des tendances idéologiques. Qu'on songe aux engagements souvent asynchroniques de la bourgeoisie et des mouvements ouvriers catalans, ainsi qu'à la capacité de dégager en Catalogne des solutions interclassistes: la Lliga catalana au début du siècle, Esquerra republicana de Catalunya durant la Deuxième République, Convergència i Unio (CIU) aujourd'hui. Au Pays basque, au contraire, la concurrence entre un courant autonomiste modéré (aujourd'hui les «statuaires» du Partido nacionalista vasco (PNV) et de Euskadico Eskerra) et un courant nationaliste (les «rupturistes» de Eusko Alkartasuna et de Herri Batasuna), dont une branche armée (ETA) ne s'est jamais éteinte. L'histoire de ces cultures politiques les a dotées de caractères très différents; bien qu'elles soient toutes deux préfigurées par les oppositions carlistes à l'Etat espagnol, la position de leurs élites dans ces luttes a fait toute la différence. Au Pays basque, les catégories dirigeantes n'ont jamais rompu avec l'appartenance nationale; le nationalisme s'est donc développé plutôt dans les classes moyennes et sous l'égide du clergé basque. II en est resté plus isolé socialement et plus radicalisé sur le plan politique. En effet, la filiation directe avec le traditionalisme catholique a inspiré un nationalisme conservateur, souvent contesté par de nouveaux groupes nationalitaires, toujours plus radicaux et plus enclins au passage à la lutte armée. Le cycle de la violence et de la répression a encore renforcé cette tendance. Le mouvement nationalitaire basque est aujourd'hui plus complexe, plus éclaté en différentes options politiques, plus instable aussi face aux enjeux contemporains, notamment face au déclin économique des régions basques: «Lorsque la conjoncture se caractérise par une tension avec le centre, il en résulte un certain unanimisme nationaliste, tandis que dans les cas qui correspondent aux situations (de plus en plus fréquentes compte tenu de la situation actuelle d'autonomie) où les problèmes interne au Pays basque peuvent être résolus politiquement, il en résulte des conflits en profondeur au sein même du mouvement nationaliste ${ }^{1}$. En Catalogne, les élites ont opté pour une séparation économique et politique, et dans ce cadre se sont développées des organisations politiques nationalitaires de

1. A. Pérez-Agote, «Silence collectif et violence politique. La radicalisation sociale du nationalisme basque », dans «Identités, espaces, frontières», Espaces et sociétés, 70 71, 1992; cf. aussi M. Heiberg, «Urban politics and rural culture: Basque nationalism», dans S. Rokkan, D.W. Urwin (eds), Politics of territorial identity. Studies in European regionalism, Londres, Sage, 1982. 
toutes obédiences. En résulte un mouvement nationalitaire plus pragmatique, plus porté à la négociation (illustré, entre autres, par la création de l'Assemblée catalane en 1971, qui coordonnait les différentes oppositions au franquisme) et plus apte à gérer les enjeux contemporains ${ }^{1}$. Ces caractères historiquement construits ont des effets importants sur le potentiel politique de ces communautés; par exemple, quant à la capacité à affronter l'enjeu de l'assimilation des immigrés, venus nombreux des autres régions espagnoles, ou quant à la capacité à porter une politique de la langue nationale; par exemple aussi, quant à la capacité à s'intégrer à la construction européenne. Face au risque de diminution des pouvoirs des communautés dans l'Union politique, la Generalitat de Catalogne a d'emblée entamé une politique européenne très volontariste, qui en fait aujourd'hui l'une des régions européennes les plus actives auprès de la CEE et dans les rapports interrégionaux européens. Elle utilise dans cette stratégie tant son potentiel économique que ses capacités de mobilisation des intérêts; par rapport au centre national, par rapport aux enjeux européens, dans le mouvement des concurrences politiques internes, le travail de construction politique du territoire est en permanence à l'œuvre.

Il apparâit donc qu'une culture politique nationalitaire n'est une ressource politique efficiente face au(x) centre(s) qu'à certaines conditions: que la situation socio-économique soit favorable à son actualisation; que se dégagent une interprétation et un mouvement politique consensuels; que le travail politique s'applique continûment à la mobilisation des représentations d'intérêts. C'est la nature de ce travail politique, en particulier dans les communautés autonomes espagnoles, qui permettra un jour de réfléchir plus avant au fait qu'un statut pragmatique attribué à des cultures politiques contestant les modalités de leur inscription dans l'ensemble national semble pouvoir constituer un processus adaptatif efficace face aux enjeux contemporains.

\section{CONSTRUCTION POLITIQUE DES TERRITOIRES ET RESSOURCES ADAPTATIVES}

Tout processus politique territorialisé peut devenir une ressource d'adaptation face à la crise de la norme étatique et des organisations politiques nationales, et face aux enjeux nouveaux de la recomposition économique et sociale dans la Communauté européenne. L'activation de cette ressource suppose un travail de construction politique, effectué par des opérateurs politiques pris dans des rapports de concurrence, notamment avec les organisations politiques nationales. Ce processus est particulièrement clair dans la phase de revendication des mouvements nationalitaires. Dorénavant, dans la mesure où ils ont en partie obtenu

1. F. Hernández, «El nacionalismo catalán », dans F. Hernández, F. Mercade (dir.), Estructuras sociales..., op. cit.; J. Corcuera, «La configuración del nacionalismo vasco $»$, ibid. 


\section{Evelyne Ritaine}

satisfaction en voyant leurs territoires dotés de statuts d'autonomie (régions à statut spécial en Italie, communautés autonomes en Espagne), cette activation joue à partir des structures institutionnelles créées; elle entraîne aussi un jeu de concurrence avec les autres territoires institutionnalisés, même lorsque ceux-ci n'ont pas connu de revendication nationalitaire. Dans la phase actuelle en Europe du Sud, les processus de concurrence politique sont donc au centre de cette construction politicoinstitutionnelle des territoires. L'échange politique se complexifie puisqu'il s'organise entre les représentations d'intérêts de chaque territoire, les différentes organisations politiques qui prétendent le représenter, les représentations d'intérêts et les organisations politiques agissant au plan national, dans des rapports de «coopération conflictuelle» plus que d'opposition. Eu égard aux modalités très différentes de la crise de la norme étatique et des organisations politiques nationales en Espagne et en Italie, on voit apparaître dans ces deux pays des processus d'adaptation liés au territoire très différents: l'Espagne semble aller vers un pluralisme politique en grande partie basé sur une logique territoriale, alors qu'en Italie se dessinent seulement pour l'instant des forces centrifuges. En revanche, ces deux pays semblent disposer, bien qu'à des niveaux organisationnels différents, de bonnes capacités de mobilisation des intérêts territorialisés, ressource précieuse dans les difficultés de l'intégration européenne.

\section{CONCURRENCES POLITICO-TERRITORIALES}

L'originalité du régionalisme politique espagnol illustre bien les différentes modalités de la construction politique puis institutionnelle du territoire. Dans le contexte difficile de la transition démocratique, on ne pouvait assister qu'à une régionalisation très politisée et à l'institutionnalisation de communautés autonomes puissantes. Les revendications nationalitaires ont été en effet des stratégies d'opposition au régime franquiste, et ont en outre permis que se réalisent des alliances entre forces antifranquistes: "Tant au Pays basque qu'en Catalogne, l'activité antifranquiste fut menée au nom de la nation opprimée, alors même que le principal était le combat pour la démocratie ou la lutte contre l'exploitation de classe ${ }^{1}$. L'un des enjeux majeurs de la transition démocratique fut donc de régler prioritairement les problèmes basque et catalan, dont la composante nationalitaire menaçait le fragile équilibre de la transition, notamment en raison de l'hostilité de l'armée et de l'administration aux processus autonomiques. La Constitution espagnole ne pouvait faire moins que de reconnâitre et d'instituer «des nationalités périphériques» (art. 2): on a pu aller jusqu'à employer à ce propos la formule de «légitimation ethnique de la démocratie» ${ }^{2}$. Ce substrat politique très fort est donc le produit direct des luttes autonomistes, et confère aux communautés autonomes issues des régions dites historiques

1. S. Giner, «Nacionalismo étnico...», art. cité.

2. Ibid. 
une légitimité fondatrice. Mais il a aussi des conséquences sur les autres communautés autonomes: en raison des difficultés politiques de la transition démocratique, le statut autonomique a été négocié de façon telle entre les forces politiques qu'il s'applique à toutes les régions espagnoles suivant des procédures à géométrie variable ${ }^{1}$. La Galice, se réclamant de son passé de région historique, a obtenu le statut maximal, comme la Catalogne et le Pays basque; l'Andalousie, portée par le militantisme de ses élites, y a également accédé par voie référendaire. Pour les autres, le statut s'applique progressivement par voie parlementaire. Cette construction institutionnelle a une véritable valeur d'instituant politique.

En effet, la logique très pragmatique de cette régionalisation et les différences entre les statuts régionaux ont enclenché une dialectique de l'affirmation des communautés face à l'Etat, et de la concurrence des communautés entre elles. Le statut autonomique a suscité la multiplication des organisations nationalitaires (souvent politiquement éphémères) de 1'Andalousie à la Navarre, de la Cantabrie aux Canaries, etc. Ce phénomène épidémique est aggravé par le surenchérissement permanent de la part des communautés catalane et basque, qui provoque les réactions des autres communautés, dans une concurrence dissimétrique: leur rapport au centre politique n'est en effet pas le même. La question du financement des communautés autonomes révèle bien cette dissimétrie: la Catalogne et le Pays basque, qui sont aussi les zones les plus riches du pays, essaient d'obtenir le maximum de liberté financière, alors que les autres, en particulier les régions plus démunies du Sud, refusent de renoncer tant soit peu au principe de la redistribution étatique. Cette logique concurrentielle est d'autant plus forte qu'elle est sous-tendue par la concurrence entre les partis politiques. Elle oppose les partis nationaux dont l'implantation locale est stable, les partis centristes (Unión Centro democrático, UCD, Alianza popular, AP, puis Partido popular, PP) puissants dans les provinces castillanes, les partis de gauche (PSOE, PCE) plus forts dans les provinces méridionales et dans les périphéries industrielles. Elle voit aussi l'affrontement de leaders locaux de partis nationaux avec leur propre parti: l'UCD a éclaté en partie en raison du développement de stratégies proprement locales. Elle se complique du fait des rapports de concurrence et de coopération qui se nouent entre partis nationaux et partis régionaux: si ces derniers sont des acteurs centraux en Catalogne et au Pays basque, ils sont également développés en Andalousie, Aragon, Galice, Navarre, et constituent des forces reconnues en Cantabrie, Valence, aux Canaries. Elle se joue enfin dans la concurrence entre partis régionaux représentatifs des différenciations idéologiques des nationalitaires catalans (CIO, Esquerra Catalana), basques (PNV/Herri Batasuna / Eusko Alkartasuna), navarrais (Union du peuple navarrais / Herri Batasuna), galiciens, etc ${ }^{2}$.

1. Il est à noter que la régionalisation espagnole s'est inspirée de la Constitution italienne et de la notion «d'Etat régional » qu'elle définit.

2. On pourrait faire la même analyse à propos du Haut-Adige, où se juxtaposent un parti autonomiste qui contrôle la junte provinciale et veille à l'application du statut d'autonomie (Südtiroler Volkspartei) et des mouvements nationalistes militant pour l'indépendance, voire la réunification avec le Tyrol autrichien (Union für Südtirol, Schützen, Leghe tirolesi), les engagements des seconds renforçant les demandes des premiers. 
Aussi peut-on penser que «dans les régions "historiques" la création des institutions régionales incarne (ou, au moins, tente d'incarner) de profonds sentiments nationalistes ou régionalistes. Dans les régions "nouvelles", où ces sentiments n'existent pas ou peu, il semble que l'enjeu soit plus le pluralisme politique que le territoire » ${ }^{1}$. Aussi est-il - possible qu'en Espagne la construction institutionnelle et politique du territoire ait été une ressource adaptative dans la transition démocratique d'abord, dans la recomposition politique nationale ensuite. La grande question des années à venir sera de savoir si l'évolution de cette construction institutionnelle et politique est une ressource ou un frein face à l'enjeu vital qu'est désormais la crise économique en Espagne: les rapports de force territoriaux iront-ils vers la coopération ou vers la concurrence, la règle du jeu sera-t-elle à la solidarité envers les zones les plus démunies ou à la différenciation à outrance?

L'un des phénomènes les plus importants de ces dernières années en Europe du Sud est sans doute la confirmation des représentations politiques à définition territoriale comme acteurs centraux de l'évolution politique. Il est révélateur qu'en Espagne les élus «nationalitaires» (dix-sept députés catalans de CIU et cinq députés basques du PNV) soient aujourd'hui en position d'arbitres pour assurer une majorité au gouvernement socialiste minoritaire ${ }^{2}$ : la négociation de leur soutien politique se déroule autour d'une accentuation de l'autonomie catalane et basque, notamment sur le plan fiscal et financier, au grand dam des communautés méridionales les plus pauvres qui revendiquent plutôt l'accentuation de la solidarité nationale et de la protection étatique. Or en Italie également la progression électorale du mouvement des Ligues, devenu la quatrième force politique du pays ${ }^{3}$, en fait désormais un acteur incontournable des alliances nécessaires pour gouverner, tant au plan national qu'au plan local (juntes municipales et régionales).

\section{POPULISME ET TERRITOIRE}

C'est par rapport à l'idée de capacité d'adaptation que la notion de construction politique du territoire met en lumière l'originalité du «localisme politique» des Ligues italiennes ${ }^{4}$. Dans ce cas, en effet, la réfé-

1. J. Botella, «The Spanish "new" regions. Territorial and political pluralism», International Political Science Review, 10 (3), 1989 (souligné dans le texte).

2. Aux élections législatives du 6 juin 1994, le PSOE s'est assuré 159 sièges et le Partido popular 141; la majorité absolue est à 176 sièges. Par ailleurs, Izquierda unida (PC élargi) obtient 18 sièges, Herri Batasuna 2, les nationalistes canariens 4 (Le Monde, 8 juin 1993).

3. Aux élections pour la Chambre des députés d'avril 1992, au plan national, la DC obtient $29,7 \%$ des suffrages exprimés et 206 sièges (sur 630); le PDS, 16,1\% et 107 sièges; le PSI, 13,6 \% et 92 sièges; la Ligue lombarde, 8,6 \% et 55 sièges. Di Virgilio, «Le elezioni in Italia», art. cité.

4. G. Rovati, «Le localisme des militants de la Ligue (lombarde) est un localisme idéologique plutôt qu'un localisme écologique», dans V. Cesareo, G. Rovati, M. Lombardi, Localismo politico: il caso Lega Lombarda, Varèse, Comitato Regionale Lombardo Democrazia Cristiana, Tipografia Varesina, 1989. Il existe cependant des nuances entre les différences Ligues régionales: pour la Ligue vénète, par exemple, les thèmes culturels sont restés importants; cf. I. Diamanti, «La mia patria è il Veneto. I valori e la proposta politica delle leghe», dans «Leghe, leghisti, legami», Polis, 2, 1992 (numéro spécial). 
rence au territoire sert d'interprétation à la crise de l'Etat, à la révolte d'une périphérie contre le centre: il s'agit d'une forme de «populisme régionaliste " ${ }^{1}$. Celui-ci se présente comme un schéma interprétatif de la crise de l'Etat: il doit son succès au fait qu'il est le seul mouvement en Italie proposant à la fois une interprétation de la crise politique et une logique d'appartenance (ce que ne peuvent pas faire les autres mouvements alternatifs, fondés sur une participation sans appartenance: mouvements écologistes, pacifistes, féministes, radicaux, antimafia), en l'occurrence une appartenance territoriale. Ce groupe d'acteurs politiques réussit une «gestion de l'hostilité » suscitée par le contexte de crise, hostilité envers les immigrés méridionaux et extra-communautaires nombreux dans le Nord industriel, hostilité envers une bureaucratie inefficace et «méridionalisée», hostilité envers le centre politique romain, méprisé par la capitale économique milanaise (le syndrome du «déséquilibre de la centralité» en Italie), hostilité de «l'homme de la rue» envers les hommes politiques discrédités, etc. La logique populiste des Ligues a su canaliser ces sentiments diffus dans une interprétation territorialisée.

Leur logique populiste ${ }^{2}$ joue sur l'opposition à l'autre, l'Etat et les partis politiques, le Sud, l'immigré. Dans une société où le localisme politique est toujours une ressource, d'autant plus au moment où les organisations nationales en perdent le contrôle, l'opposition peut aisément être traduite en termes d'appartenance territoriale: ici le Nord, contre Rome et contre le Sud. La façon dont la Ligue lombarde a réussi à imposer les thèmes d'une appartenance lombarde puis nordiste est révélatrice de ces processus de construction politique. Il n'est pas sans intérêt de remarquer que les principaux dirigeants de la Ligue lombarde, dont U. Bossi son leader, se sont formés au contact du mouvement autonomiste de l'Union valdotaine; leur base idéologique est alors celle d'un régionalisme classique, prétendant rassembler sur la base de l'appartenance culturelle ${ }^{3}$. Or l'espace régional n'est pas en Italie, hors les régions ethno-linguistiques, un espace d'intégration politique, laquelle demeure locale; en Lombardie moins qu'ailleurs sans doute, tant il est vrai qu'il s'agit d'une zone profondément transformée par l'industrialisation, la présence de la mégalopole milanaise (où vit la moitié de la population régionale) et l'immigration méridionale. Aussi bien la Ligue n'y obtint-elle longtemps que des résultats électoraux modestes. C'est en 1989 qu'elle parvient à se constituer en acteur politique d'envergure nationale, en mettant au point un «schéma interprétatif», le populisme régionaliste, qui lui permet désormais de capter à son profit l'exaspération des citoyens de l'Italie la plus développée et d'étendre l'implanta-

1. R. Biorcio, «La lega come attore politico: dal federalismo al populismo regionalista », dans R. Mannheimer (dir.), La Lega lombarda, op. cit.

2. Au sens dans lequel l'emploie R. Biorcio, «La lega come...», art. cité, des formations politiques caractérisées par «la rupture des codes symboliques des idéologies et organisations politiques traditionnelles, l'appel au "sens commun" contre les hommes politiques et les intellectuels, le retour à des traditions communautaires "authentiques" et la référence à des personnalités charismatiques».

3. «Peu importent votre âge, votre activité professionnelle, votre tendance politique : l'important est que vous soyez tous, que nous soyons tous, lombards », dans Lombardia autonomista, 1, 1982, cité par R. Biorcio, «La Lega come...», art. cité. 
tion politique des Ligues à d'autres régions. A partir de cette date en effet, on voit reculer les thèmes spécifiquement culturels, comme la revendication du dialecte lombard, par exemple. La thématique centrale devient celle de l'opposition de l'homme de la rue et des milieux politiques, de la société civile et des partis, du Nord (soucieux de gérer luimême ses richesses fiscales) et du Sud (considéré comme dilapidant l'argent public au profit de structures clientélistes et mafieuses): cette hostilité prend sens au travers de l'affirmation des valeurs «territorialisées» (c'est-à-dire qualifiées de lombardes) du travail et de l'efficacité opposées à la carence de l'appareil d'Etat. Le populisme régionaliste échappe ainsi aux polarisations sémantiques habituelles du champ politique, droite/gauche, catholique/laïc, démocrate/fasciste, classe ouvrière/patronat, etc., qui sont précisément en crise.

«Le modèle politique proposé par la Ligue lombarde apparaît comme une combinaison originale entre régionalisme et orientations populistes. Ce modèle semble très efficace car il assume, dans l'actuelle situation italienne, une connotation très significative: l'exaltation des valeurs lombardes du travail et de l'efficacité de l'initiative privée, par opposition aux carences de l'appareil d'Etat, a attribué au vote pour la Ligue un sens général de révolte et de revendication d'un certain type de société civile "saine" envers les milieux politiques. La lecture que la Ligue fournit de la crise politique utilise une métaphore puissante: la polarisation Lombardie/Rome symbolise efficacement les tensions entre société civile et système des partis, et fournit aux citoyens un référent collectif concret auquel ils peuvent donner une valeur positive dans le conflit. ${ }^{1}$ »

La logique d'appartenance mise en place permet d'occuper en partie l'espace politique laissé vacant par les partis de masse, dans lequel l'intégration politique se réalisait au travers de toute une série d'associations liées aux partis: l'appartenance lombarde est sensée jouer le même rôle, en même temps que tirer l'appartenance vers l'espace plus moderniste de référence qu'est la région (glissement qu'ont échoué à réaliser les régions institutionnelles). Enfin, au thème de la revendication régionaliste s'est substitué le thème du fédéralisme des trois Italie, dans lequel la centralité politique reviendrait à l'Italie la plus puissante, celle des «régions padano-alpines, communauté multirégionale de même culture $»^{2}$. L'espace de l'action politique est ainsi étendu à l'ensemble du système politique italien. La progression électorale ${ }^{3}$ et sans doute, plus encore, l'écho rencontré dans la société italienne ont consacré ce travail politique, d'autant plus efficace tant que n'apparaît pas d'alternative politique crédible au plan national. La Ligue lombarde est en effet la principale manifestation de ce qu' on a pu nommer le «vote difforme "

1. Ibid.

2. Premier congrès de la Ligue lombarde, 1989, cité par R. Biorcio, ibid.

3. Aux élections pour la Chambre des députés d'avril 1992, la Ligue lombarde emporte (sur les suffrages exprimés) $23 \%$ des voix en Lombardie, 17,8\% en Vénétie, $16,3 \%$ en Piémont, $15,3 \%$ en Frioul-Vénétie julienne; $14,3 \%$ en Ligurie; $9,6 \%$ en Emilie-Romagne; 8,9 \% en Trentin-Haut-Adige; 3,1\% en Toscane; plus au Sud son score devient négligeable. Di Virgilio, «Le elezioni in Italia», art. cité.

4. M. Caciagli, A. Spreafico (dir.), Vent'anni di elezioni in Italia, 1968-1987, Padoue, Liviana, 1990. 
celui qui abandonne les choix électoraux traditionnels, représentés par les partis politiques «historiques» au profit d'un vote «transversal» (écologiste, radical, antimafia, etc. ${ }^{1}$ ) ou $\mathrm{d}^{\prime}$ un vote "localiste $»^{2}$, voire, aux dernières élections municipales, d'un vote protestataire en faveur du parti néo-fasciste (MSI): les élections législatives anticipées de mars 1994 vont montrer comment s'effectue la recomposition politique italienne autour de cette transformation, et, en particulier, si les coalitions de gauche sont capables de bâtir une alternative.

L'enjeu contemporain est, comme en Espagne, vital: 1'Italie est sommée d'affronter une très grave crise économique et sociale avec un appareil d'Etat disqualifié, des structures de représentation en lambeaux, une fragmentation territoriale qui va jusqu'à la fragmentation politique. Pour l'heure, tous les processus politiques nouveaux font figure de symptômes, non de remedes, alors que des choix fondamentaux s'imposent, en matière d'institutions politiques, d'intégration nationale, de principe de redistribution.

\section{TERRITOIRE ET REPRÉSENTATION DES INTÉRÊTS}

Le potentiel politique d'un territoire est aussi fonction du degré de mobilisation des représentations d'intérêts. Les organisations d'intérêts se déterminent surtout selon une «logique du membership», c'est-à-dire celle de leurs expériences organisationnelles et des enjeux de leurs membres $^{3}$. Soit il existe des intérêts fortement localisés, comme dans la troisième Italie, et ceux-ci recherchent la coopération avec 1'instance politique la plus efficace pour la gestion de leurs problèmes. Soit les intérêts ne sont pas spécialement localisés, et il revient aux acteurs politiques de faire la démonstration de leur efficience stratégique; ainsi en est-il, par exemple, des politiques régulatives régionales (aménagement de l'espace, gestion de l'environnement, intervention sur le marché local du travail, etc.) qui peuvent susciter la mobilisation des représentations d'intérêts ${ }^{4}$. En ce sens, la puissance institutionnelle, d'une part, la légitimité politique des élus, d'autre part, sont des catalyseurs de la mobilisation de ces organisations, mobilisation qui vient à son tour renforcer le potentiel politique du territoire.

1. Federazione dei Verdi, PR, Lista Pannella, Lista Referendum, Rete-Movimento democratico.

2. Partis nationalitaires du Val d'Aoste et du Trentin-Haut-Adige, Lega lombarda, Lega veneta, autres listes localistes.

3. C.P. Schmitter, L. Lanzalaco, «L'organizzazione degli interessi...», art. cité ; cf. aussi D. Coleman, H.J. Jacek (eds), Regionalism, Business interests and public policy, Londres, Sage, 1989.

4. Comme c'est le cas pour les Lander par exemple: «Ce n'est pas la nature de la demande, mais la façon dont les pouvoirs décisionnels et la responsabilité politique sont distribués entre les différents niveaux de gouvernement, qui détermine à qui sont adressées les demandes. Parce que les gouvernements régionaux allemands sont très influents aussi bien en termes de pouvoirs décisionnels qu'en termes de ressources financières, les organisations d'intérêts régionales sont fortement incitées à agir comme des acteurs autonomes. Cela a contribué à renforcer encore plus le modèle décentralisé d'organisation des intérêts, né à l'origine de conditions historiques particulières », dans $R$. Mayntz, «Regioni e rappresentanza degli interessi : il caso tedesco», Stato e Mercato, 2, 1990. 
Le néolocalisme italien est exemplaire de la forme de régulation moderne que peut apporter une capacité de négociation territorialisée. Dans le contexte des subcultures politico-politiques du Centre et du Nord-Est italiens, on s'est attaché à étudier les conditions contemporaines de l'échange politique. C'est à propos de ces contextes de très forte régulation socio-politique locale qu'est née la notion de neolocalismo, pour expliciter la réactualisation de cet héritage dans les enjeux contemporains de l'industrialisation diffuse qu'ont dû affronter ces territoires ${ }^{1}$. Face à la déstabilisation sociale et à l'incertitude que génère ce mode de développement fondé sur la flexibilité et la coopération de multiples acteurs économiques, l'homogénéité des contextes politiques locaux, leur organisation intensément réticulaire ont permis qu'émerge une médiation localisée des intérêts. La régulation néolocaliste s'analyse comme un modèle de négociation permanente, organisée localement, qui «s'exprime par une combinaison de structures fonctionnelles (syndicats, organisations catégorielles et d'entrepreneurs) qui interagissent entre elles et avec le gouvernement local à l'intérieur de zones spécifiques, et de structures de représentation territoriale (parti, commune) qui favorisent la régulation par leurs interventions et par l'action exercée aux niveaux régionaux et centraux. Ce processus est influencé par le contexte subculturel qui fournit des ressources pour l'organisation des intérêts, mais qui conditionne également les modalités d'interaction des différents acteurs du système politique local $»^{2}$. En portant une attention particulière aux représentations d'intérêts, on le définit comme «la division particulière du travail entre marché, structures sociales et, de façon croissante, structures politiques, qui permet une flexibilité élevée de l'économie et une capacité d'adaptation rapide aux variations du marché, mais aussi une redistribution des coûts sociaux et des avantages du développement à l'intérieur de la société locale» ${ }^{3}$.

Cependant, cette régulation localisée, héritière des appartenances municipales italiennes, ne s'exprime vraiment qu'à l'échelon municipal, voire à l'échelon provincial qui en est le relais normal en raison de l'organisation provinciale des structures partisanes et syndicales. Les régions italiennes, au contraire, ne parviennent que rarement à structurer l'échange politique à leur niveau. En raison de la «conception minimaliste» des régions que la mauvaise volonté de l'appareil d'Etat puis les difficultés budgétaires ont imposée, elles ne constituent pas des bases décisionnelles stratégiques ${ }^{4}$. De plus, les représentations d'intérêts ne se

1. Dans C. Trigilia, «La regolazione localista: economica e politica nelle aree di piccola impresa », Stato e Mercato, 14, 1985: «Nous voulons attirer l'attention sur deux conséquences (de la présence de subcultures politiques territorialisées): l'existence d'un réservoir de ressources pour l'organisation des intérêts et l'influence sur un mode de représentation sensiblement conditionné par des liens économiques et politiques locaux».

2. Ibid.

3. Ibid.

4. R.D. Putnam, R. Leonardi, R.Y. Nanetti, La pianta e le radici, op. cit.; C. Trigilia, «Il paradosso della regione: regolazione economica e rappresentanza degli interessi », Meridiana, 6, 1989. 
sont que rarement organisées au niveau régional, privilégiant plutôt les niveaux locaux et national. La régulation territorialisée en Italie demeure donc pour l'heure essentiellement basée sur une dynamique sociale et politique localisée, ratant, par là même, une possibilité de régulation plus ample et mieux adaptée aux enjeux contemporains. Seules quelques régions au bargaining politique particulièrement énergique échappent à cette faiblesse: la Lombardie, par exemple, qui est parvenue à d'intéressantes performances programmatiques (dans un contexte national particulièrement défavorable en la matière), en partie parce qu'elle a pour partenaires des associations d'entrepreneurs puissantes et mobilisées; par contraste, l'Emilie-Romagne, région exemplaire pour les politiques sociales et environnementales, n'est pas parvenue à tisser des relations stables avec les représentations d'intérêts économiques au niveau régional '.

Comparativement, les communautés autonomes espagnoles les plus puissantes paraissent disposer d'un potentiel politique fortement adaptatif $^{2}$. C'est ainsi que la Generalitat de Catalogne a pour objectif politique majeur de renforcer son potentiel politique face au pouvoir central, d'une part, face aux pouvoirs politiques infra-régionaux, d'autre part (notamment face à la municipalité de Barcelone, tenue par les socialistes, alors que la Generalitat est aux mains de centristes nationalitaires ${ }^{3}$ ). Elle dispose pour ce faire d'importantes compétences législatives. Elle peut en particulier réformer son organisation territoriale et ne s'en est pas privée: de façon à faire converger vers elle et à contrôler politiquement les représentations d'intérêts, elle a dissous l'institution métropolitaine de Barcelone, qui tendait à rassembler les intérêts économiques les plus dynamiques, et mis en sommeil les provinces au profit de l'institution intermédiaire de la comarca, chargée de la coopération inter-communale. Dans ce cadre renouvelé, elle favorise la création d'échelons régionaux de représentation des intérêts quand ceux-ci n'existent pas ${ }^{4}$; puis elle assure l'intégration des représentations d'intérêts dans le processus de décision politique en multipliant, notamment en matière de politique économique, les instances mixtes de participation. Elle potentialise ainsi, sur le plan politique, la très ancienne tradition d'associationnisme des milieux socio-économiques catalans. Ces représentations régionales se sont d'ailleurs souvent intégrées à des représentations nationales pour faire face aux exigences de la négociation au sein de la CEE, et elles y

1. R. Leonardi, R.Y. Nanetti (dir.), The regions and European integration. The case of Emilia-Romagna, Londres, New York, Pinter, 1990.

2. Du moins le suppose-t-on, en l'absence d'informations, pour les communautés autonomes puissantes, la quasi-totalité des travaux sur les représentations d'intérêts étant consacrée à la Catalogne.

3. PSOE (P. Maragal) à la mairie de Barcelone, CIU (J. Pujol y Soley) au gouvernement de la Generalitat.

4. J. Tornos Mass, «Regionali e rappresentanza...», art. cité; cf. aussi C. Sole, «Regionalism and the organization of business interests in the Spanish textile-industry », dans W.D. Coleman, H.J. Jacek (eds), Regionalism..., op. cit.; D. Sidjanski, U. Ayberk (eds), L'Europe du Sud dans la Communauté européenne. Analyse comparative des groupes d'intérêts et de leur insertion dans le réseau communautaire, Paris, PUF, 1990. 
jouent un rôle moteur. Par cet «échange politique institutionnalisé » basé sur un substrat d'intégration socio-politique régionale hérité, la communauté autonome catalane travaille à s'assurer un poids politique stratégique dans un système d'échange politique très complexe.

On peut supposer que la construction européenne, en majorant l'importance des instances régionales de gouvernement, ne fera qu'accroître les différences de potentiel politique territorial: les analystes du néocorporatisme pensent en effet que la construction européenne est un facteur de dérégulation pour les tendances néocorporatistes, et qu'elle va provoquer la généralisation d'échanges pluralistes, tant au niveau de la Communauté que des Etats, sommant ainsi les gouvernements régionaux et locaux à de sévères adaptations à la concurrence ouverte et au bargaining politique permanent ${ }^{2}$.

Evelyne Ritaine est chargée de recherche au Centre d'étude et de recherches sur la vie locale (Fondation nationale des sciences politiques). Elle est l'auteur de "Territoire: espace du jeu politique», Quaderni, 13-14, 1991 et de "La modernité localisée? Leçons italiennes sur le développement régional », Revue française de science politique, 39 (2), avril 1989. Elle a publié récemment (en collaboration avec Richard Balme, Philippe Garraud, Vincent Hoffmann-Martinot) "Les politiques territoriales en Europe de l'Ouest», Revue française de science politique, 43 (3), juin 1993. Elle travaille actuellement sur les processus territoriaux, les villes et les médiations politiques en Europe du Sud (CERVL, Institut d'études politiques de Bordeaux, BP 101, 33405 Talence).

1. F. Cazzola, «L'associazionismo istituzionalizzato», dans M. Fedele (dir.), Il sistema politico locale, Bari, De Donato, 1983.

2. W. Streeck, C.P. Schmitter, «From national corporatism to transitional pluralism. Organized interests in the Single European Market», Politics and Management, 2, 1991. 
Il y a deux ans, le 15 mars 1992, Annick Percheron nous quittait, après un combat d'un courage admirable qui avait presque fini par nous faire croire à l'impossible. Membre du Conseil de l'Association française de science politique, du nouveau Comité de rédaction de la Revue française de science politique, directeur de l'Observatoire interrégional du politique, elle avait donné son temps et son énergie à la recherche.

Le premier texte qui suit, inédit, est l'histoire de son itinéraire intellectuel, tel qu'elle l'avait elle-même présenté pour sa soutenance de thèse. Puis, après l'hommage de René Rémond, Jacques Lagroye, analysant les textes réunis par Nonna Mayer et Anne Muxel, en montre la dynamique et le constant approfondissement. Et c'est une Annick Percheron vivante que l'on entend parler ici.

Jean-Luc Parodi 